\title{
An examination of daily activities and their scripts across the adult lifespan
}

\author{
V. M. ROSEN and L. CAPLAN \\ National Institute of Mental Health, Bethesda, Maryland \\ L. SHEESLEY \\ National Institute of Neurological Disorders and Stroke, Bethesda, Maryland \\ R. RODRIGUEZ \\ National Institute of Mental Health, Bethesda, Maryland \\ and \\ J. GRAFMAN \\ National Institute of Neurological Disorders and Stroke, Bethesda, Maryland
}

\begin{abstract}
In two normative studies, we examined daily scripted activities from the perspective that scripts are frequency-based knowledge structures. In Study 1, individuals recorded their daily activities for 7 consecutive days. Fifteen activities that were reported with low, moderate, and high frequency were selected for Study 2, in which individuals generated a script for each activity. The 18 most frequently generated events from each script are reported, along with their centrality and distinctiveness rankings and the number of individuals reporting each event. Overall, the mean number of events generated increased with increasing script frequency, suggesting that script representations are subject to frequency effects. Also, we found a high level of consistency across the three age groups in the events generated in each script and in their corresponding rankings of centrality and distinctiveness. Finally, we found no evidence of age or gender bias in the frequency or recency of engaging in each of the scripted activities.
\end{abstract}

Schank and Abelson (1977) proposed a theory about world knowledge, in which they argued that individuals store scripts in memory for activities that they engage in repeatedly, such as eating in a restaurant. They described scripts as causal sequences of events within specific contexts (see Miller, Galanter, \& Pribram, 1960, for an earlier but similar theory about plans and structured activities). In the decades that followed Schank and Abelson's script theory, a number of studies emerged that explored the nature of script representation (Abbott, Black, \& Smith, 1985; Barsalou \& Sewell, 1985; Bower, Black, \& Turner, 1979; Galambos, 1983; Galambos \& Rips, 1982; Haberlandt \& Bingham, 1984; Hue \& Erickson, 1991; Nottenburg \& Shoben, 1980; Sirigu et al., 1996). An examination of Table 1 reveals that a wide array of task instructions and procedures were used in these studies and that a wide array of findings emerged with respect to the relevant dimensions involved in script representation. Although the nature of script representation continues to be an important research topic, it is beyond the scope of this paper. Instead, the present set of normative studies was designed as a first

Correspondence concerning this article should be addressed to V. M. Rosen, National Institute of Mental Health, Geriatric Psychiatry Branch, 10 Center Drive, Building 10, Room 3N228, Bethesda, MD 20892 (e-mail: rosenv@intra.nimh.nih.gov). step in examining script representation from the perspective that scripts are frequency-based knowledge structures (Grafman, 1995).

Grafman (1995) argued that scripts result from repeated experience with activities and events and that sequential information about script events is stored as a separate domain of knowledge in the frontal lobes and is subject to frequency effects, as are other domains of knowledge, such as language. Support for frequency-based storage in the frontal lobes was found in a study conducted by Sirigu et al. (1995). In our search through the literature, we found little in the way of normative studies that collected information about the frequency of engaging in daily activities, particularly across the adult lifespan. Therefore, in the present set of studies, we first examined the frequency of engaging in daily activities for three age groups (i.e., young, middle-aged, and older). We then had the three age groups generate scripts for a subset of these activities. We used the studies listed in Table 1 as a guide in choosing relevant script variables for the present set of studies. We examined age and gender differences in the total number of events generated for each script, as well as in the number of idiosyncratic events, at each level of script activity frequency (i.e., low, moderate, and high). We also examined the frequency of reporting each event in a script, along with its corresponding ranking of centrality and distinctiveness. 
Table 1

A Comparison of Procedures and Findings in Previously Conducted Script Studies

\begin{tabular}{|c|c|c|c|}
\hline Research Study Participants & $\begin{array}{c}\text { No. Scripts } \\
\text { Generated }\end{array}$ & $\begin{array}{l}\text { Instructions and } \\
\text { Procedures }\end{array}$ & Findings \\
\hline Galambos (1983) 67 young & $\begin{array}{l}30-\text { not } \\
\text { generated }\end{array}$ & $\begin{array}{l}\text { rate } 12 \text { actions in scripts on } \\
\text { centrality, distinctiveness, } \\
\text { standardness and sequence; } \\
\text { wrote responses; } \\
\text { no time limit }\end{array}$ & $\begin{array}{l}\text { relationship found between centrality } \\
\text { and standardness (frequency), but not } \\
\text { between centrality and sequence or } \\
\text { between centrality and distinctiveness }\end{array}$ \\
\hline Bower, Black, \& Turner (1979) 161 young & 5 & $\begin{array}{l}\text { generate approximately } 20 \\
\text { actions and put in correct order; } \\
\text { looking for "common actions"; } \\
\text { wrote responses; } \\
\text { no time limit }\end{array}$ & $\begin{array}{l}\text { few unique actions produced }(0.5 \%-7 \%) \text {; } \\
\text { relationship found between centrality } \\
\text { and frequency of reporting action; } \\
\text { centrality information came from } \\
\text { Barsalou's unpublished norms }\end{array}$ \\
\hline Barsalou \& Sewell (1985) 24 young & 8 & $\begin{array}{l}4 \text { conditions: unconstrained, most } \\
\text { to least central, } 1 \text { st to last, last to } 1 \text { st; } \\
\text { generate actions quickly in correct } \\
\text { order, at middle level of abstraction; } \\
\text { spoke responses; } \\
\text { 20-sec time limit }\end{array}$ & $\begin{array}{l}\text { generated greatest no. of actions in } \\
1 \text { st to last condition (forward order); } \\
\text { relationship found between output } \\
\text { position and centrality and between } \\
\text { temporal position and centrality }\end{array}$ \\
\hline $\begin{array}{l}\text { Light \& Anderson }(1983) \\
46 \text { young and } 56 \text { older }\end{array}$ & 6 & $\begin{array}{l}\text { generate approximately } 20 \\
\text { actions and try not to include } \\
\text { idiosyncratic actions; } \\
\text { actions later normed for typicality; } \\
\text { wrote responses; } \\
\text { no time limit }\end{array}$ & $\begin{array}{l}\text { no age differences for total no. of actions } \\
\text { or no. of idiosyncratic actions }(16 \%-26 \%) \text {; } \\
\text { no age differences in event typicality; } \\
\text { no age differences in relationship } \\
\text { between typicality and frequency of } \\
\text { reporting an event }\end{array}$ \\
\hline Ross \& Berg (1992) 30 young and 30 older & 2 & $\begin{array}{l}\text { give enough detail so others } \\
\text { will know exactly what you did; } \\
\text { spoke responses; } \\
\text { no time limit }\end{array}$ & $\begin{array}{l}\text { older adults produced more } \\
\text { idiosyncratic actions than young; } \\
\text { about } 1 / 3 \text { of events were idiosyncratic }\end{array}$ \\
\hline Hess (1992) 20 young and 21 older & 4 & $\begin{array}{l}\text { describe in detail and use } \\
\text { activity's temporal order as } \\
\text { guide; } \\
\text { spoke responses; } \\
\text { no time limit }\end{array}$ & $\begin{array}{l}\text { greatest age differences found in no. of } \\
\text { idiosyncratic actions produced for } \\
\text { less constrained activities; } \\
\text { about } 1 / 3 \text { of actions were idiosyncratic } \\
\text { and } 60 \% \text { of those were age unique }\end{array}$ \\
\hline $\begin{array}{l}\text { Grafman et al. (1991) } 74 \text { older } \\
\quad \text { (31 controls, } 14 \text { depressed and } 29 \text { DAT patients) }\end{array}$ & 1 & $\begin{array}{l}\text { generate as many events } \\
\text { as possible; } \\
\text { spoke or wrote responses; } \\
\text { no time limit }\end{array}$ & $\begin{array}{l}\text { no group differences in relationship } \\
\text { between production order and centrality; } \\
\text { centrality information came from } \\
\text { Barsalou's unpublished norms }\end{array}$ \\
\hline $\begin{array}{l}\text { Sirigu et al. (1995) } 33 \text { older ( } 16 \text { controls, } \\
9 \text { prefrontal and } 8 \text { posterior lesion patients) }\end{array}$ & 3 & $\begin{array}{l}\text { routine, nonroutine, and novel scripts; } \\
\text { correct order was not emphasized; } \\
\text { spoke responses; } \\
\text { no time limit }\end{array}$ & $\begin{array}{l}\text { no group differences in total no. of events; } \\
\text { no group differences in frequency of } \\
\text { reporting an action; } \\
\text { frontals made most sequence errors } \\
\text { in nonroutine and novel scripts }\end{array}$ \\
\hline
\end{tabular}

\section{STUDY 1}

In the first study, we were primarily interested in determining which daily activities, on average, are engaged in with low, moderate, or high frequency by having individuals keep a journal of their daily activities for 7 consecutive days. On the basis of the average frequency of reporting the activities, we could then establish a list of activities that ranged along a frequency continuum from activities that were reported only once by a single individual during the week (e.g., being in a car accident/low frequency), to activities that were reported more than once by most or all of the individuals during the week (e.g., getting ready for work/high frequency). On the basis of our frequency continuum, we could then choose a set of activities from three locations along the continuum (low-, moderate-, and highfrequency activities) and have individuals generate scripts for those activities in the second study. Finally, in order to make the data useful to a wide range of researchers (including ourselves), we collected data on an equal number of women and men in three age groups: young, middleaged, and older.

\section{Method}

Participants. One hundred forty-nine participants were recruited from the greater Washington, D.C. area and were paid for their participation. However, only 120 returned their completed booklets and met the age or health requirements for this study. Although we were concerned because some of the booklets had not been returned, the return rate did not appear to bias our sample. All the participants read and signed a consent form that was approved by the Institutional Review Board of the National Institutes of Health. The 120 participants that were included in this study consisted of 20 females and 20 males in each of three age groups: young (18-30 years old), middle-aged ( $35-50$ years old), and older (55-75 years old). All of the 120 individuals reported that they were healthy, with no prior histories of neurological or psychiatric disorders or learning disabilities, and were not taking any antidepressant or psychotropic medications at the time of testing. The demographic information is presented in Table 2.

Materials. Each journal booklet contained nine sheets: a cover sheet, an example sheet, and seven sheets on which the participants 
Table 2

Demographic Information for the Participants in Each Study

\begin{tabular}{|c|c|c|c|c|c|c|c|c|c|c|}
\hline \multirow[b]{3}{*}{ Participants } & & & \multicolumn{4}{|c|}{ Age (in Years) } & \multicolumn{4}{|c|}{ Years of Education } \\
\hline & \multicolumn{2}{|c|}{ Number } & \multicolumn{2}{|c|}{$\mathrm{F}$} & \multicolumn{2}{|c|}{$\mathrm{M}$} & \multicolumn{2}{|c|}{$\mathrm{F}$} & \multicolumn{2}{|c|}{$M$} \\
\hline & $\mathrm{F}$ & $\bar{M}$ & $M$ & $S D$ & $M$ & $S D$ & $M$ & $S D$ & $M$ & $S D$ \\
\hline \multicolumn{11}{|c|}{ Study 1} \\
\hline Young & 20 & 20 & 25 & 3.95 & 23 & 4.14 & 15 & 2.07 & 15 & 2.33 \\
\hline Middle-aged & 20 & 20 & 41 & 4.24 & 41 & 4.30 & 16 & 2.39 & 16 & 2.18 \\
\hline Older & 20 & 20 & 67 & 5.70 & 67 & 6.48 & 15 & 2.31 & 16 & 2.42 \\
\hline \multicolumn{11}{|c|}{ Study 2} \\
\hline Young & 10 & 10 & 23 & 3.94 & 22 & 3.50 & 16 & 2.31 & 15 & 2.35 \\
\hline Middle-aged & 10 & 10 & 42 & 4.65 & 41 & 4.64 & 16 & 1.14 & 16 & 2.07 \\
\hline Older & 10 & 10 & 65 & 4.27 & 66 & 3.82 & 15 & 1.91 & 16 & 2.46 \\
\hline
\end{tabular}

wrote their daily activities for seven consecutive days. The first sheet of the booklet contained instructions, along with demographic and medical history questions. The second sheet contained a sample day of activities, to be used as a guide in filling out the seven daily journal sheets in the booklet. A copy of the sample sheet appears in Appendix A. Each sheet in the booklet had a different day of the week printed at the top, with a place to the right of it to record the date. Each sheet was divided into 24 one-hour time slots, which began at 1 a.m. and ended at midnight of the same day.

Procedure. The individuals came into the lab to read and sign a consent form and receive their booklet to take home and fill out. The majority of the booklets were completed between the early summer and the mid fall months. We expected to find some seasonal bias in reported activities, but we also expected that most activities would be relatively free of seasonal bias (e.g., getting ready for work, going out to dinner). The participants were told to use the sample sheet in the booklet as a guide when recording their own activities and to record their activities every $2-3 \mathrm{~h}$ during the day, using a minimum amount of detail. We did this because we wanted only a general idea about daily activities in the first study and we were concerned that the participants would be less likely to complete the booklet if told to record a lot of detail about their activities. We also expected that the scripts generated in the second study would provide us with greater detail about activities.

If the participants received their booklet before noon, they were told to begin recording their activities with the current day; otherwise, they should wait until the next day to begin. Also, if the participants were about to leave on vacation, they were told to start recording their activities when they returned. Each participant was given a stamped, preaddressed envelope in which to return the completed booklet.

\section{Results}

Scoring. All activities were recorded in a spreadsheet, which contained a total of 381 activity categories. The large number of activity categories precluded us from reporting the entire data set here. However, the complete data set is available to researchers upon request.

Four types of categories were predetermined to help structure the scoring of the booklets: meals, transportation, personal grooming, and house cleaning. Five categories were assigned to each of the three meals (breakfast, lunch, and dinner) - eating, eating at home, eating out, prepared by self, and prepared by others-for a total of 15 meal categories. There were 14 transportation categories: transporting self, transporting others, transported by others, carpooling, riding a motorcycle, riding a bicycle, walk- ing, riding a metro bus, riding a metro train, riding a shuttle bus, riding a trolley, taking a train (e.g., Amtrak), taking a taxi, and taking a plane. Two separate categories were created for morning and evening grooming because they often involved different actions. Finally, 7 housecleaning categories were created: cleaning the kitchen, cleaning the bedroom, cleaning the bathroom, washing dishes, doing the laundry, ironing clothes, and general housecleaning. The general housecleaning category included activities that were less detailed or room-specific such as straightening up and vacuuming the house.

The remaining activity categories were not predetermined, and category creation was based on activity overlap. If an activity did not overlap with other activities, a unique category was created, such as balancing the checkbook. In contrast, activities such as drinking water and drinking soda require the same basic actions but differ with respect to superficial features (i.e., type of liquid), and so both would be scored as drinking a nonalcoholicbeverage. The participants received one point for each time that they reported engaging in an activity, even when the activity began and ended at different times within a single day. For example, starting the laundry, then working in the yard, and then completing the laundry on the same day would result in adding only one point to the doing the laundry category.

All of the activities were rank ordered according to frequency of reporting. The selection of the 15 activities that became scripts for the second study involved a two-step process. First, the lower $20 \%$, the median $8 \%$, and the upper $20 \%$ of the rank-ordered activities were designated as low-, moderate-, and high-frequency ranges from which to choose candidate activities. We chose the median instead of the mean $8 \%$ for the moderate range, because the distribution of ranks was positively skewed and we wanted to gain greater separation between moderate- and low-frequency activities. Second, four of the five authors on this paper separately selected 5 candidate activities from each of the three frequency ranges. Any activities that were not selected by more than two authors were eliminated as candidate activities, and the selection process was repeated until all four authors agreed on a final set of 15 activities. We strove to choose activities that would not severely constrain the number of events that could be gen- 
erated in a script, so that activity constraints would not become an unwanted variable in our frequency analyses. For example, numerous events could be generated for a going out to dinner script. In contrast, a brushing your teeth script would severely constrain the number of events that could be generated, even though both of the aforementioned activities might be considered high frequency. We also strove to choose activities that were free of age or gender bias. However, this was a difficult feat to accomplish, especially with the low-frequency activities, because some activities were reported by only 1 individual. It is important to keep in mind that not reporting an activity does not mean that an individual has never engaged in that activity in their lifetime; it means only that they did not engage in that activity during their week of journal keeping. We felt that any activity that was reported by all individuals was, by implication, a high-frequency activity, even if it was reported only once by all of the individuals. Any fears that could be raised concerning age or gender bias in reporting were dispelled by the self-reports that accompanied script generation in Study 2. We had the participants tell us when they had last engaged in each of the 15 activities, after they had finished generating each of the scripts. We found no evidence of age or gender bias in their self-reports. The analyses that were conducted on these reports are presented in the Study 2 Results section.

The mean frequency of reporting the low-, moderate-, and high-frequency activities and the number of individuals reporting are displayed in Table 3 by age group and gender. The five low-frequency activities that were chosen were going to a theatre audition, going to a funeral, going scuba diving, having your picture taken by a professional photographer, and being in a car accident. The five moderatefrequency activities that were chosen were going to the dentist, shopping for clothes, going bowling, giving a party, and painting a house. The five high-frequency activities that were chosen were going out to dinner, getting ready for work, doing the laundry, shopping for groceries, and putting a child to bed.

\section{STUDY 2}

In the second study, we took the 15 activities that were selected from the first study and had young, middle-aged, and older individuals generate a script for each activity. In addition to generating the events involved in each of the 15 script activities, we also had the individuals rank each event with respect to its level of centrality and distinctiveness in the script (Galambos, 1983). As a final measure, we had the participants report how long it had been since they had last engaged in each of the 15 activities. We were interested in whether recency of engaging in an activity in Study 2 would map onto the frequency of reporting an activity from Study 1. Also, we wanted to gather additional evidence that the 15 activities that were chosen from Study 1 were free of age and gender bias.

\section{Method}

Participants. Sixty-seven participants were recruited from the greater Washington, D.C. area and were paid for their participation. All the participants read and signed a consent form that was approved by the Institutional Review Board of the National Institutes of Health. Of the 67 participants who completed the study, 6 were dropped because they did not follow instructions ( 2 young females, 3 middle-aged females, 1 middle-aged male), and 1 older female was dropped because she reported that she had experienced a serious head injury in the past. The remaining 60 participants who were included in this study consisted of 10 females and 10 males in each of three age groups: young (18-30 years old), middle-aged (35-50 years old), and older (55-75 years old). All of the 60 individuals reported that they were healthy, with no prior histories of neurological or psychiatric disorders or learning disabilities, and were not taking any antidepressant or psychotropic medications at the time of testing. All the participants were tested during the summer months. The demographic information is presented in Table 2.

Design. The experimental design was a 2 (gender) $\times 3$ (age group) $\times 3$ (script frequency) split-plot factorial design, where gender and age group were between-subjects variables and script frequency was a within-subjects variable. The two levels of gender were female and male; the three levels of age group were young, middle-aged, and older; and the three levels of script frequency were low, moderate, and high. There were 10 participants in each of the six between-subjects cells, for a total of 60 participants.

Materials. The 15 activities that were selected by the judges in the first study were listed in a booklet for the second study. The 1st page contained instructions, at the top of the page, for filling out the booklet, followed by a sample script for touring a farm. A copy of the sample sheet appears in Appendix B. The remaining 15 pages had a single activity printed at the top of a page, followed by 20 numbered lines on which to write each of the events involved in performing that activity. We did not instruct individuals as to number of events to generate, as to whether they should record the events in the correct order, or as to whether we were looking for a certain level of abstraction or detail in their entries. The order of presentation for the 15 activities in each booklet was randomly determined, so that

Table 3

Mean Frequency of Reporting Low-, Moderate-, and High-Frequency Activities, With Number of Individuals Reporting Each Activity, for Each Age Group and Gender in Study 1

\begin{tabular}{|c|c|c|c|c|c|c|c|c|c|c|c|c|c|c|c|}
\hline \multirow[b]{4}{*}{ Activity } & \multicolumn{15}{|c|}{ Age Group } \\
\hline & \multicolumn{5}{|c|}{ Young } & \multicolumn{5}{|c|}{ Middle-Aged } & \multicolumn{5}{|c|}{ Older } \\
\hline & \multicolumn{2}{|c|}{$\mathrm{F}$} & \multicolumn{2}{|c|}{$\mathrm{M}$} & \multirow{2}{*}{$\begin{array}{c}\text { Mean } \\
\text { Freq. }\end{array}$} & \multicolumn{2}{|c|}{$\mathrm{F}$} & \multicolumn{2}{|c|}{$\mathrm{M}$} & \multirow{2}{*}{$\begin{array}{c}\text { Mean } \\
\text { Freq. }\end{array}$} & \multicolumn{2}{|c|}{$\mathrm{F}$} & \multicolumn{2}{|c|}{$\mathrm{M}$} & \multirow{2}{*}{$\begin{array}{l}\text { Mean } \\
\text { Freq. }\end{array}$} \\
\hline & Freq. & No. & Freq. & No. & & Freq. & No. & Freq. & No. & & No. & Freq. & No. & Freq. & \\
\hline Low & 0.00 & 0 & .03 & 3 & 0.01 & 0.01 & 1 & 0.01 & 1 & 0.01 & 0.00 & 0 & 0.00 & 0 & 0.00 \\
\hline Moderate & 0.10 & 4 & .04 & 3 & 0.07 & 0.06 & 4 & 0.06 & 5 & 0.06 & 0.09 & 5 & 0.01 & 1 & 0.05 \\
\hline High & 2.39 & 69 & 1.75 & 50 & 2.07 & 2.81 & 75 & 1.81 & 54 & 2.31 & 2.40 & 70 & 1.79 & 55 & 2.09 \\
\hline Mean & 0.83 & & .61 & & & 0.96 & & 0.63 & & & 0.83 & & 0.60 & & \\
\hline
\end{tabular}

Note-F, female; M, male. 
no two booklets were alike. There were two short lines that appeared to the right of each of the 20 numbered lines on each page, on which the individuals would later place their rankings after generating all of the scripts. Finally, a single short line appeared on the far right of the first numbered line, on which the individuals were to write down how long it had been since they had last engaged in the activity.

Procedure. The participants were tested in small groups in the lab, and the experimenter was present for the entire session, which lasted approximately $90 \mathrm{~min}$. The participants were told that they should write down the sequence of events associated with each activity, to the best of their knowledge, from the very beginning of the activity until its completion. They were given 3 min to write down the events for each activity, which was timed by the experimenter with a stopwatch.

After generating events for all of the 15 scripts, the individuals were told to go back and rank each of the events in each of the 15 scripts. The ranking task was not timed. The instructions that were given were similar to those used by Galambos (1983), but our procedure was different. The instructions appear in their entirety in Appendix $\mathrm{C}$. The individuals were first told that they were to rank order each event that they generated in each script with respect to how "central" the event was to the activity. An event was described as central if the activity could not occur without the event's having occurred. For example, buying a ticket is central to traveling on a plane, because you cannot board the plane without one. After completing the centrality rankings, the individuals were told to go back and rank order each of the events in each of the 15 scripted activities with respect to the "distinctiveness" of each event. An event was described as distinctive if it would be difficult to imagine the event as part of another activity. For example, being required to put your tray in an upright position (for takeoff) is distinctive to traveling on a plane, because it is difficult to imagine another activity that would include that event. For both types of rankings, individuals were told to place a 1 next to the most central/ distinctive event, a 2 next to the second most central/distinctive event, and so on until they had rankordered all of the events in each of the 15 scripted activities. Finally, the individuals were told to go back and write down how long it had been since they had last engaged in each of the activities (in hours, days, weeks, months, or years or never).

\section{Results}

Scoring. The individuals who scored the booklets were blind with respect to age group, gender, and script frequency. All of the 15 script activities were entered in a single column of a spreadsheet, and the events that were generated by each participant were entered below each script activity header. Each event was unique and did not always reflect the exact wording of an event generated by an individual. For example, one individual may have stated that he or she walked out of the house, whereas another individual may have stated that he or she went outside, both prior to getting into their car to drive to work. A left the house event would have been created to represent these analogous events. Bower et al. (1979) similarly combined analogous events when they were scoring their script data. Any new events that were entered in the script column conformed roughly to the episodic sequence of the script in the booklet. For example, if a participant stated that he or she got out of bed at the beginning of his or her getting ready for work script, the event was entered in the column near the beginning of the script sequence. We entered all of the events in this manner so that we could later place the 18 most frequently generated events in an episodic order that was in keeping with the order of reporting in the booklets. The mean total number of events that were generated by all of the individuals at each level of script frequency were 112 for the five low-frequency scripts, 107 for the five moderate-frequency scripts, and 115 for the five high-frequency scripts. After all of the events were entered in the spreadsheet, the frequency totals for each event were computed by going back through the booklets a second time and marking down each time an event was stated by an individual in a script. The events in each script activity were then sorted by frequency of reporting. The report frequencies and event rankings associated with the 18 most frequently generated events in each script were used in the analyses. The decision to choose the 18 most frequently generated events was purely arbitrary and was directed mainly at having sufficient data for correlational analyses. Finally, script generation errors were rare, and so no error analyses were conducted on the script data.

Mean length of time since last engaging in an activity. After the participants had completed the script generation and rankings portion of the task, we had them report how long it had been since they had last engaged in each of the 15 activities - in hours, days, weeks, months, years, or never. The self-reports were converted into numbers reflecting the six time ranges: $1=1 \mathrm{~h}$ to 1 day, $2=$ 2 days to 1 week, $3=8$ days to 1 month, $4=1$ month to 1 year, $5=1$ year + , and $6=$ never engaged in the activity. We submitted the mean length of time for each individual at each level of script frequency to a 2 (gender) $\times 3$ (age group) $\times 3$ (script frequency) split-plot factorial analysis of variance (ANOVA) with gender and age group as between-subjects variables and script frequency as a within-subjects variable. We found a main effect of script frequency $\left[F(2,108)=663, M S_{\mathrm{e}}=0.16, p<.0001\right.$; means of 5.13, 4.14, and 2.49 for low-, moderate-, and high-frequency activities], reflecting that the length of time since last engaging in an activity decreased with increasing script frequency. This finding also suggested that recency of engaging in an activity in the present study mapped onto the frequency of reporting an activity from Study 1. Also, an interaction was found between gender and script frequency $\left[F(2,108)=5.42, M S_{\mathrm{e}}=0.16, p<.01\right.$; women, means of 5.23, 4.14, and 2.36 for low-, moderate-, and high-frequency activities; men, mean of 5.02, 4.14, and 2.63 for low-, moderate-, and high-frequency activities]. The gender $X$ script frequency interaction indicated that slightly more time had elapsed for the women than for the men since they had last engaged in the low-frequency activities and that slightly less time had elapsed for the women than for the men since they had last engaged in the high-frequency activities. Despite this interaction, there was little indication of any age or gender bias found in the length of time that had elapsed since the individuals had last engaged in the 15 activities. No other main effects or interactions were found.

Mean total number of events generated. We submitted the mean total number of events generated by each individual at each level of script frequency to a 2 (gender) $\times$ 3 (age group) $\times 3$ (script frequency) split-plot factorial ANOVA with gender and age group as between-subjects 
variables and script frequency as a within-subjects variable. The top half of Table 4 contains the mean number of events generated for each age group and gender at the three levels of script frequency. We found main effects of gender $\left[F(1,54)=5.20, M S_{\mathrm{e}}=20.74, p<.05\right]$, age group $\left[F(2,54)=7.21, M S_{\mathrm{e}}=20.74, p=.001\right]$, and script frequency $\left[F(2,108)=78.77, M S_{\mathrm{e}}=1.41, p<.0001\right]$. Women generated slightly more events than did men, overall. The young individuals generated the greatest number of events, followed by the older and then the middle-aged individuals. Overall, the number of events generated increased with increasing script frequency. However, an age group $\times$ script frequency interaction was found $\left[F(4,108)=3.58, M S_{\mathrm{e}}=1.41, p<.01\right]$. Simple main effect comparisons indicated that the mean total number of events generated significantly increased with increasing script frequency for the young $[F(2,54)=$ $10.25, M S_{\mathrm{e}}=6.84, p<.001$, and middle-aged $[F(2,54)=$ $\left.4.36, M S_{\mathrm{e}}=8.16, p<.05\right]$ individuals, but not for the older individuals $\left[F(2,54)=1.79, M S_{\mathrm{e}}=8.56, p<.20\right]$.

Mean proportion of total events generated that were idiosyncratic. For each individual, at each level of script frequency, we calculated a proportion score for the percentage of events generated that were idiosyncratic (i.e., reported by only 1 individual). The bottom half of Table 4 contains the mean proportions for each age group and gender at the three levels of script frequency. We submitted the proportion scores to a 2 (gender) $\times 3$ (age group) $\times$ 3 (script frequency) split-plot factorial ANOVA with gender and age group as between-subjects variables and script frequency as a within-subjects variable. There were no significant main effects or interactions found for any of the three variables. Overall, there was a low occurrence of idiosyncratic events, with proportions ranging between .03 and .10 across the three levels of script frequency and the three age groups.

Frequency, centrality, and distinctiveness. Because we found little in the way of gender differences in the previous analyses, the remaining analyses were collapsed across gender. Table 5 contains the 18 most frequently generated events for each of the 15 script activities. The scripts are presented in order from low to high frequency. Frequency of reporting appears to the immediate right of each of the 18 events in each script. The mean proportional rankings for centrality and distinctiveness appear to the right of the frequency column, with an "All Ages" column appearing first that reflects the rankings collapsed across the three age groups, followed by the mean rankings for the three separate age groups. Proportional ranks were defined as the proportion of events in a script that were ranked as less central, or distinctive than the event in question. We used proportional ranks instead of the raw rank values because the raw values did not reflect the total number of events generated in a script. For example, 2 individuals might rank the same event in a script as a 5 in its level of centrality. However, a ranking of 5 would carry different levels of importance, or centrality, if one individual had generated a total of 6 events, whereas the other individual had generated a total of 15 events. Recall, that ranking values increased with decreasing levels of centrality and distinctiveness. Consequently, an event with a centrality ranking of 5 would be considered far more central to a script if a total of 15 events had been generated than if only 6 events had been generated. Finally, the mean total number of events generated in each script appears at the top of each column, next to the script heading.

Correlations among centrality, distinctiveness, and event frequency. We conducted intraclass correlations ${ }^{1}$ on the mean proportional rankings of centrality and distinctiveness and the frequency of reporting each of the 18 events, in each of the 15 scripts. Table 6 contains the intraclass correlations, which reflect the level of agreement among the three age groups. The analyses were conducted at the level of the group mean, rather than the individual, because we did not have a complete set of ranking data for any of the individuals. Recall that we chose the 18 most frequently generated events on the basis of scripts that were generated by our 60 participants, who ranked their own events immediately after generating the scripts. In contrast, Galambos (1983) had all of his participants rank identical

Table 4

Mean Total Number of Events Generated in Study 2 and Mean Proportion of Total Events Generated That Were Idiosyncratic (i.e., Reported by Only 1 Individual) for Each Age Group and Gender (With Standard Deviations)

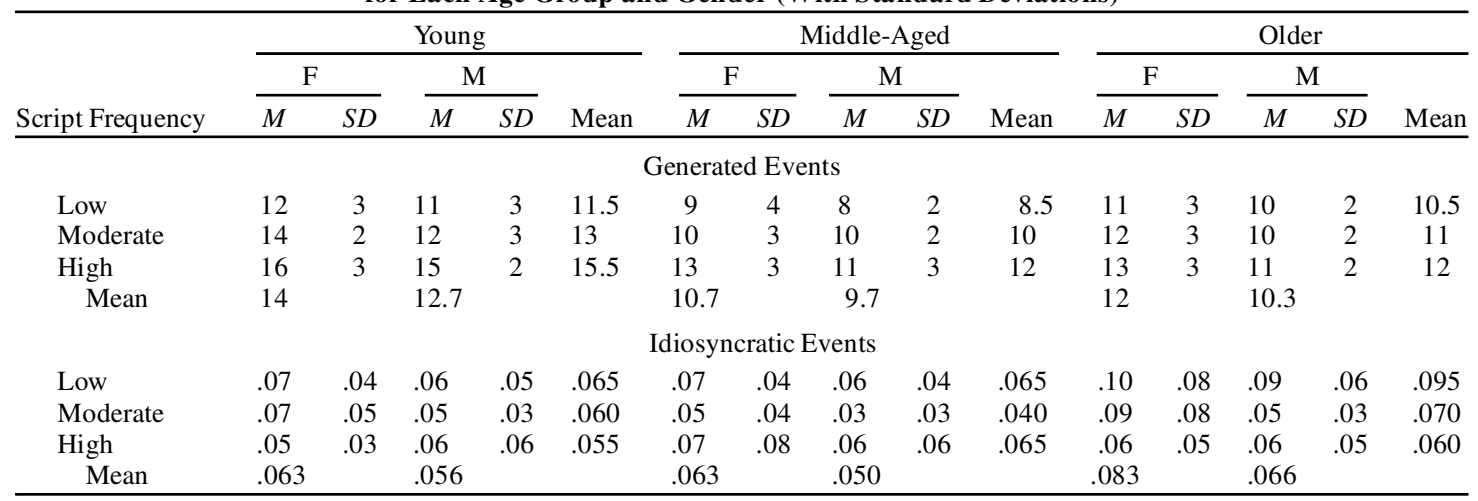

Note-F, female; M, male. 


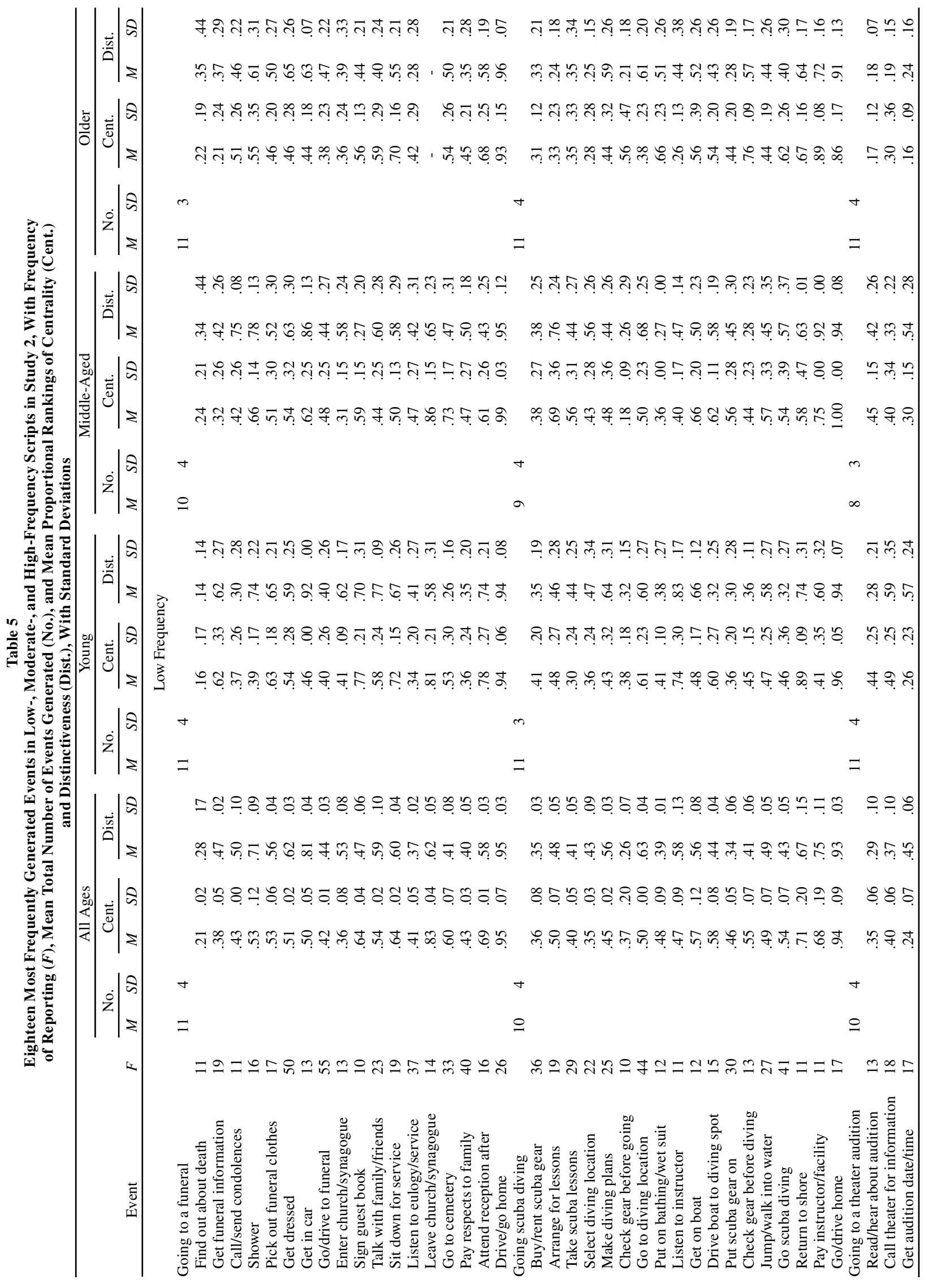




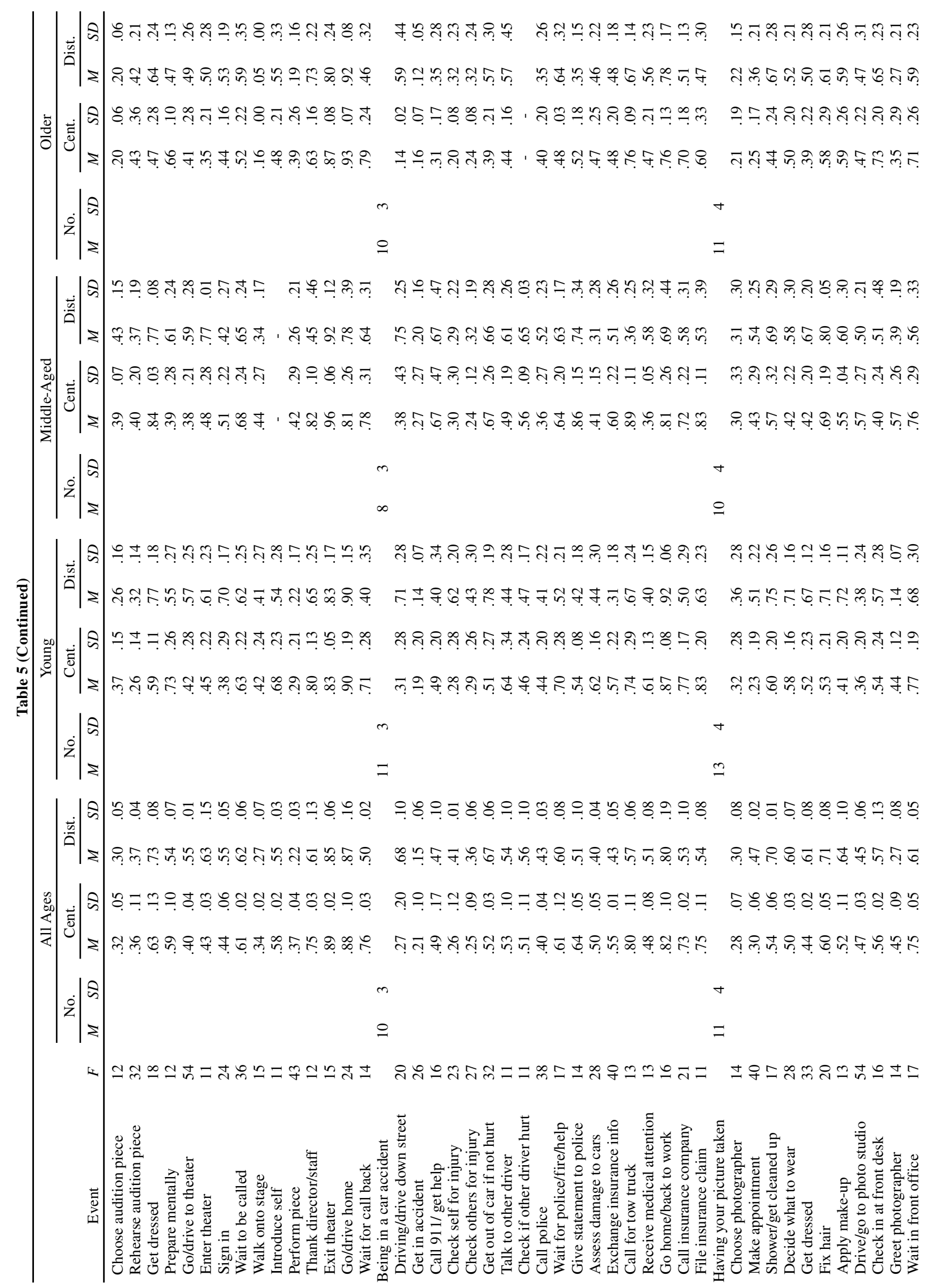




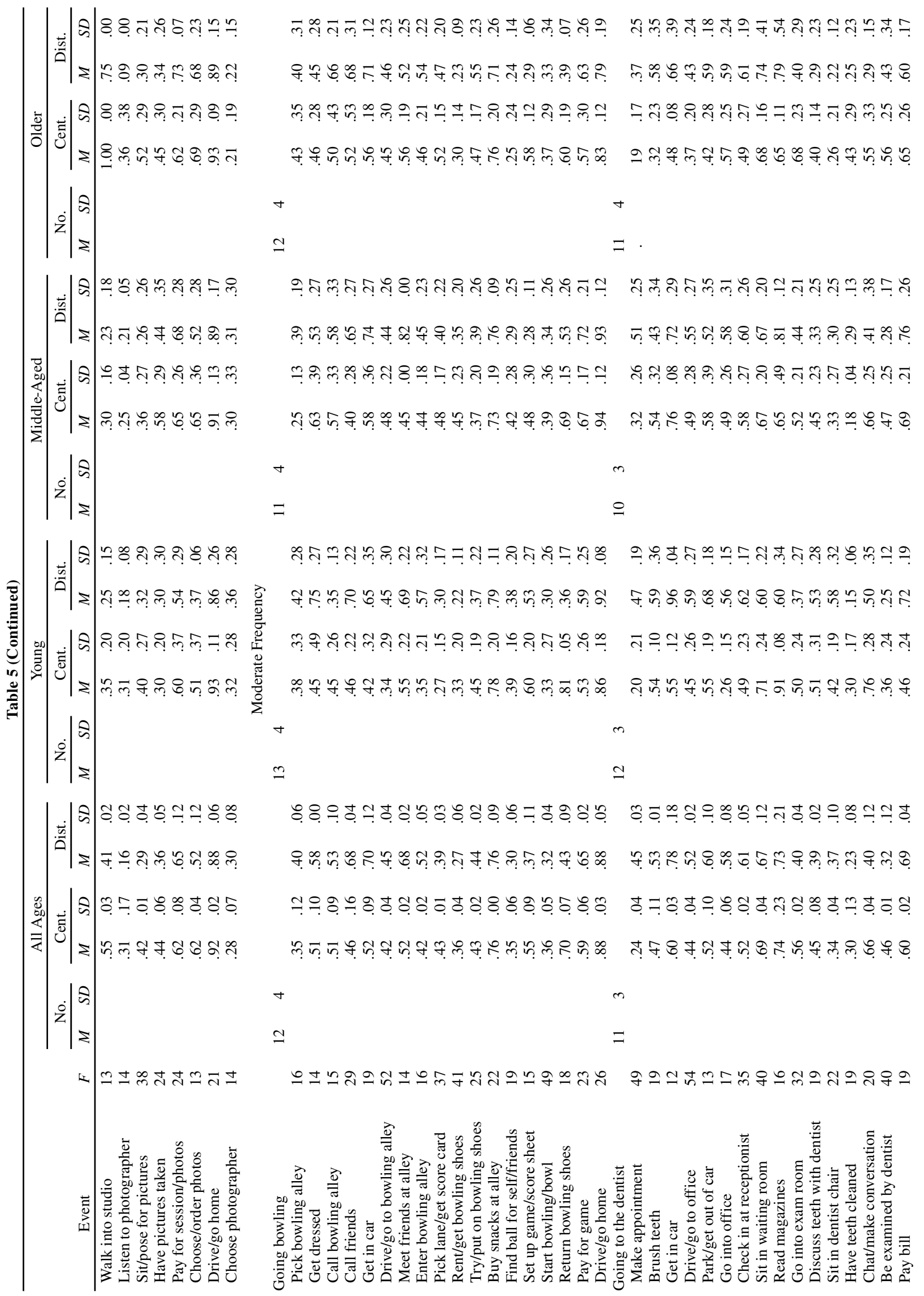




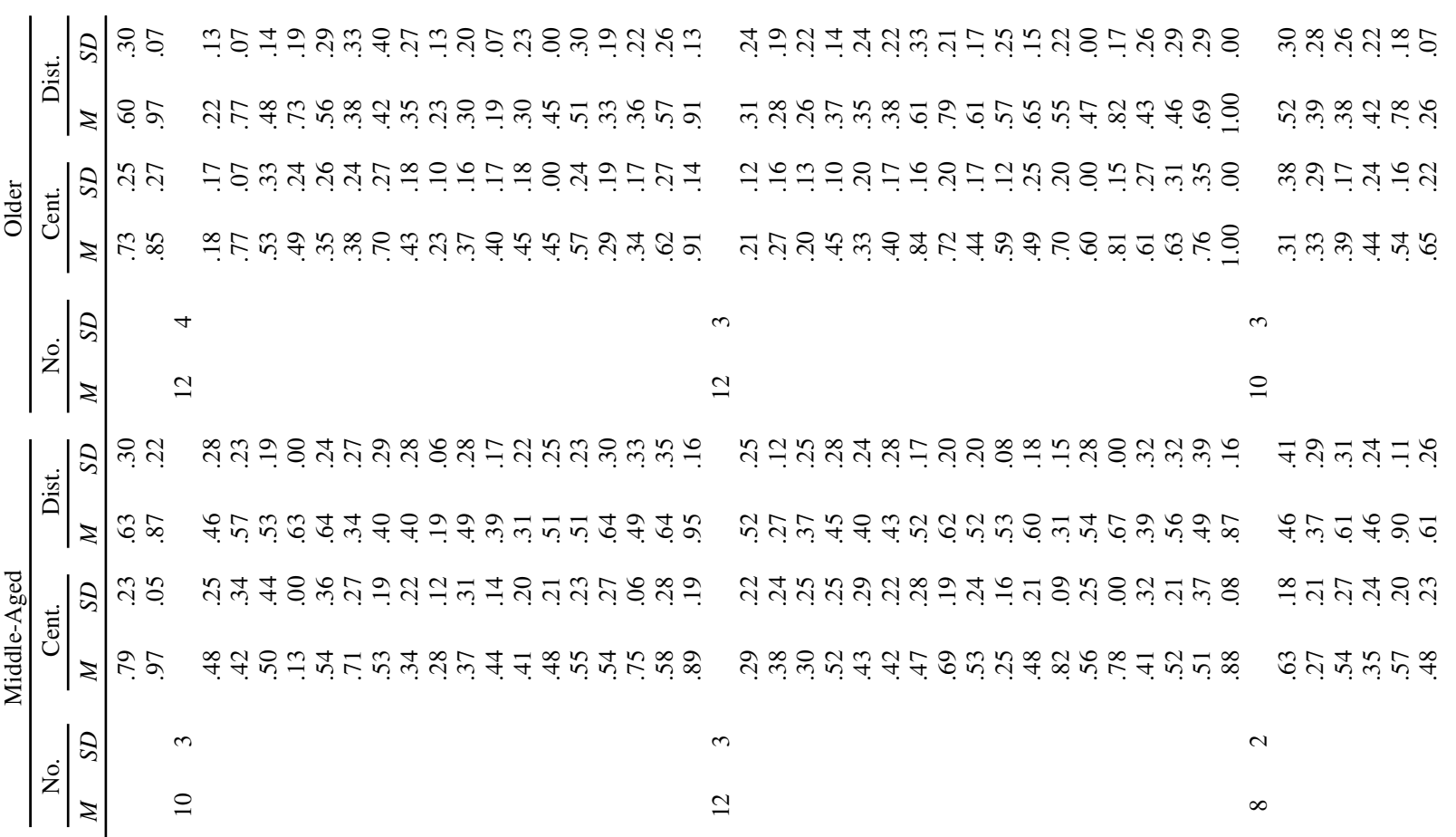

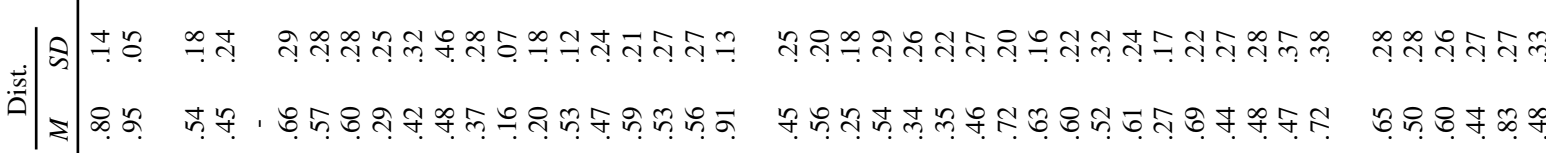
㺃

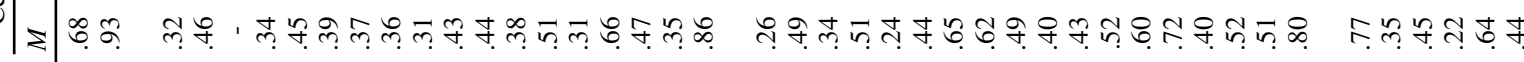
$\dot{\mathrm{z}}$ $+$ $\sin$ $\ddot{\vec{n}}$

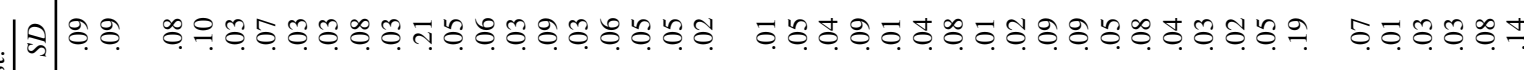
ヌ

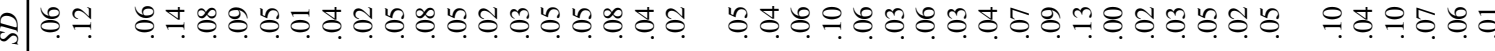

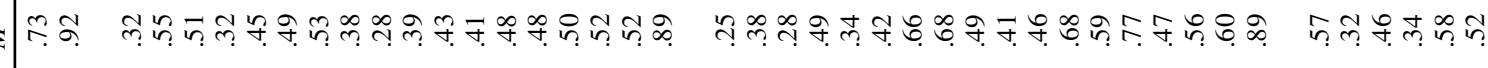

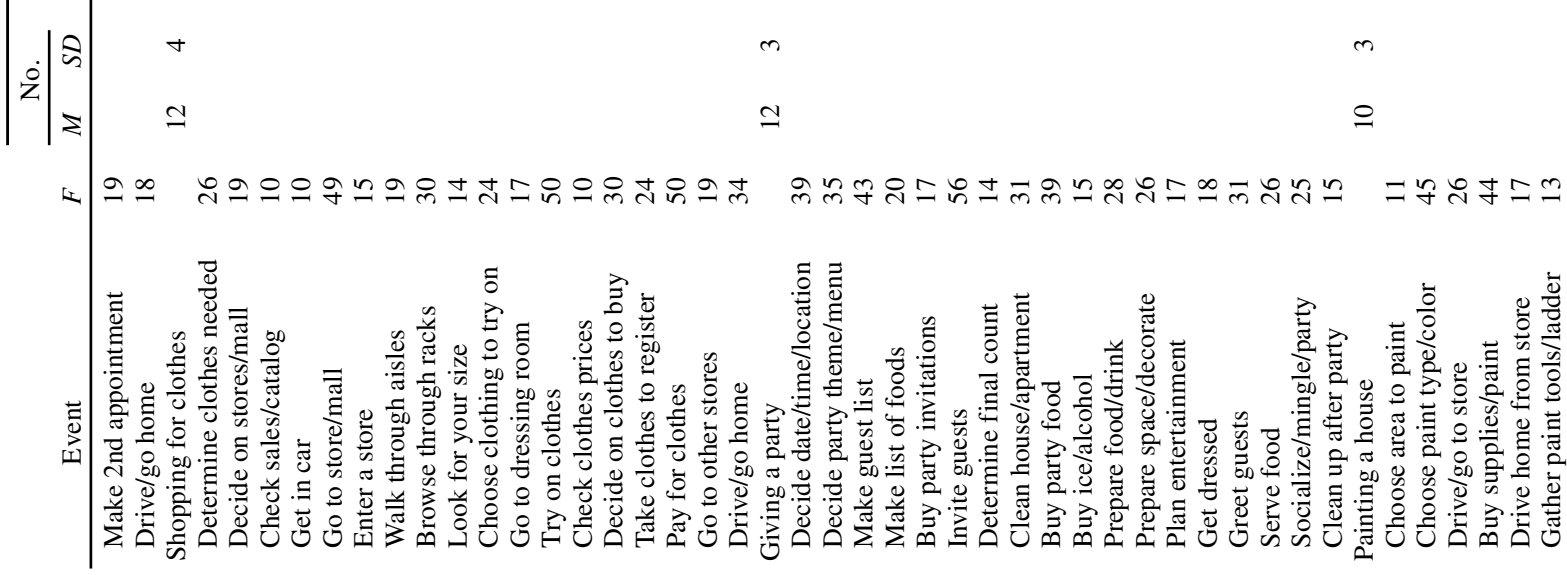




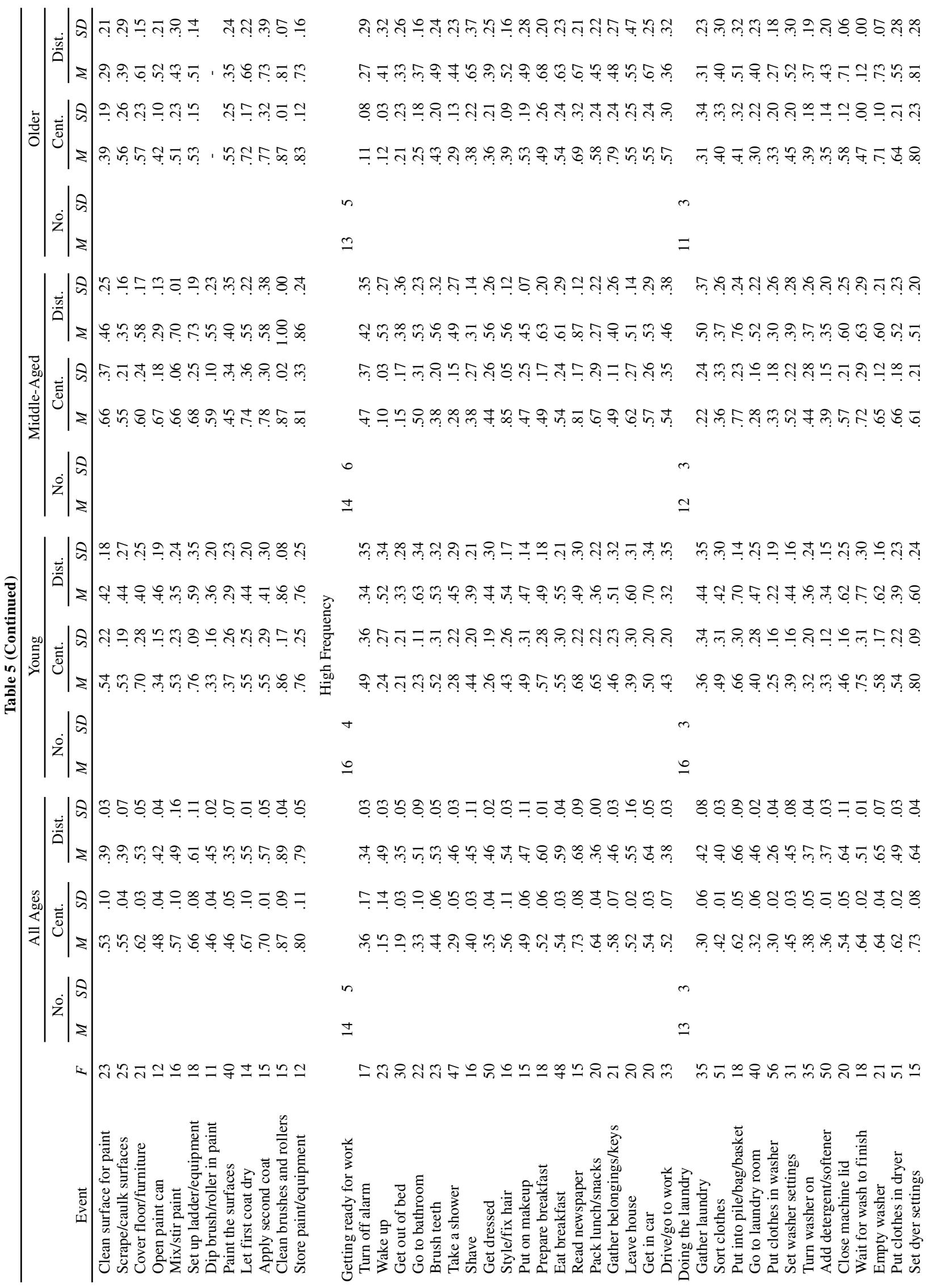




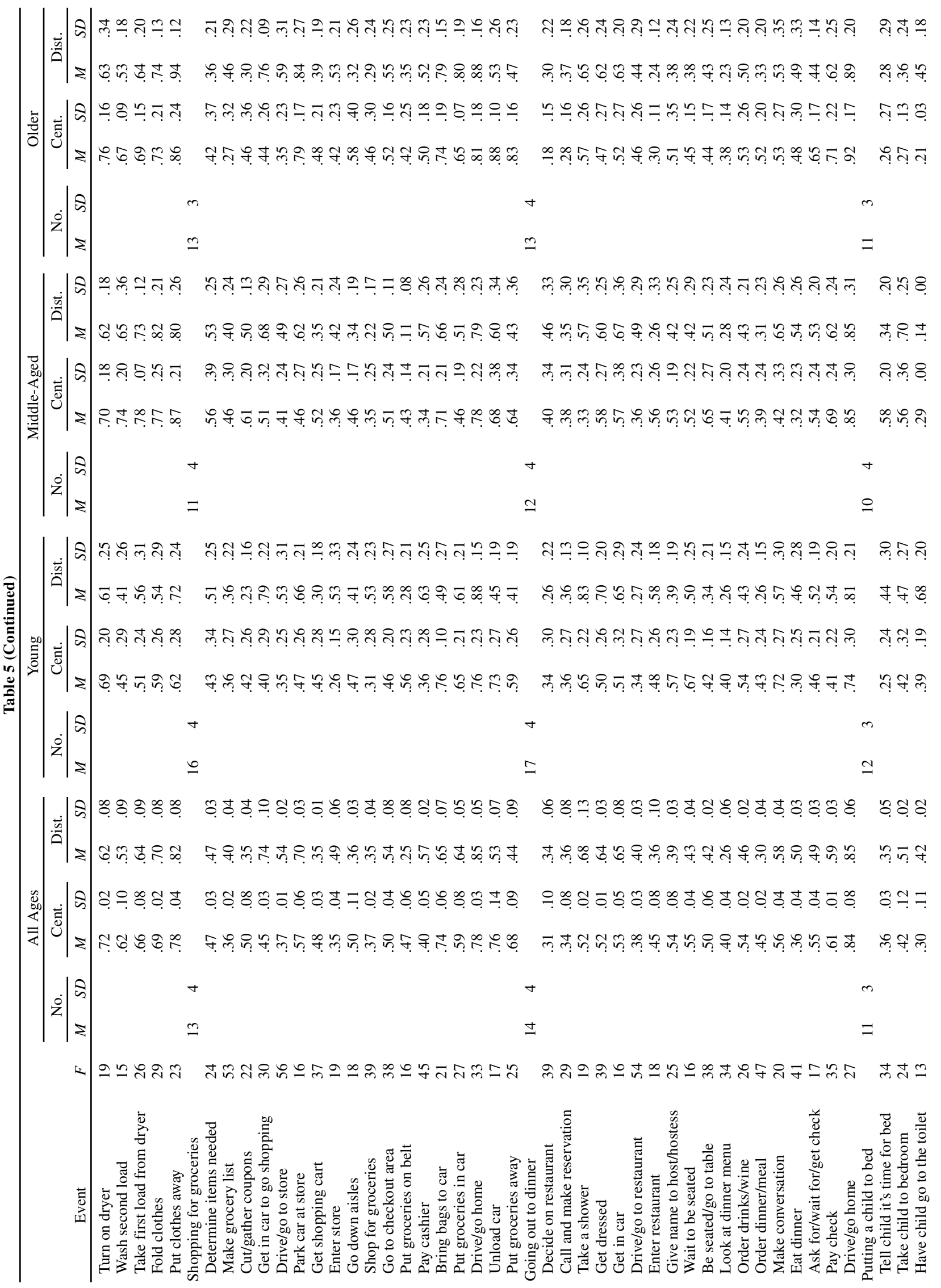




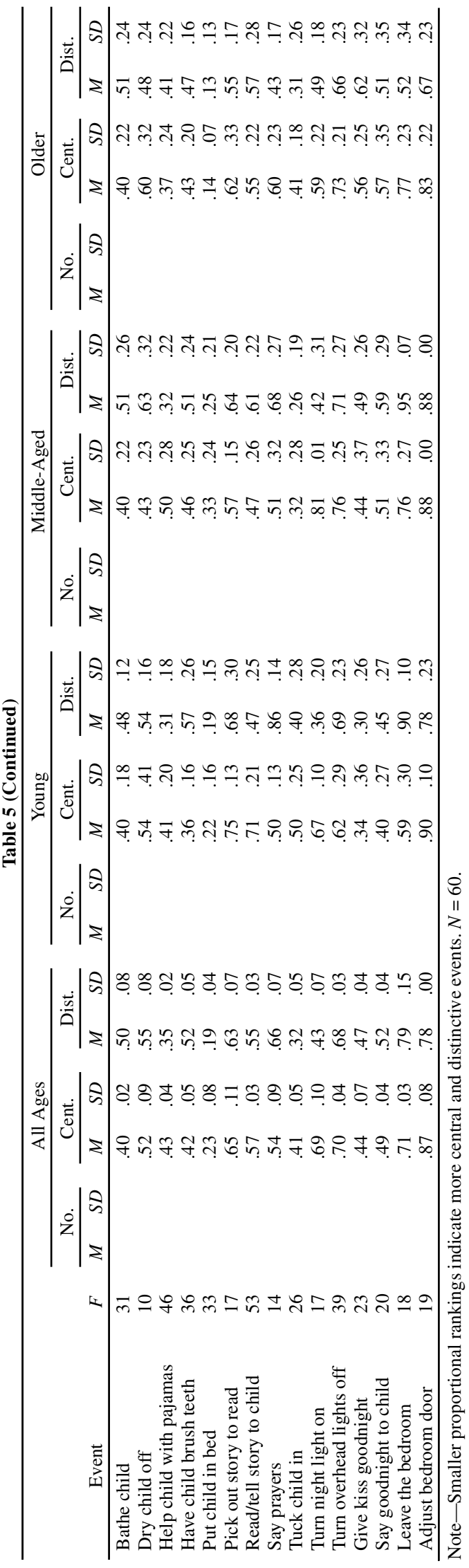

events from identical preselected scripts and so was able to examine agreement at the level of the individual.

The intraclass correlations that we conducted were based on a random-effects model and were tested using an $F$ ratio (see note 1 ) of the between-item error to the residual error (Shrout \& Fleiss, 1979). An examination of Table 6 reveals some correlations that share the same level of magnitude (e.g., .66) but different significance values. The reason for this anomaly is that the intraclass correlation includes between-group error in its denominator, which can attenuate the correlation, whereas the $F$ test for the significance of the correlation does not. We used the more conservative method of calculating intraclass correlations on the basis of the individual, rather than the group mean, because of the small number of items in each analysis $(n=18)$. All but 2 of the 45 intraclass correlations in Table 6 were significant, indicating that there was a good amount of agreement among the three age groups in their rankings of centrality and distinctiveness and in the frequency of reporting the events in each script. Consequently, we collapsed across age group before conducting the rank order correlations among centrality, distinctiveness, and frequency that are reported in Table 7.

Table 7 contains the rank order correlations among frequency of reporting each event in a script and the proportional rankings for centrality and distinctiveness, collapsed across age group and gender. The relationship between frequency of reporting an event and its corresponding ranking of centrality was found to be significant in only 2 of the 15 scripts ( 1 each in the moderate-, and the high-frequency scripts). The correlations were negative for the most part and ranged between -.66 and .12 across the three levels of script frequency. These findings suggested that the centrality and event frequency dimensions were relatively independent, as were the distinctiveness and event frequency dimensions. The correlations between distinctiveness and event frequency were negative for the most part and ranged between -.67 and .10 across the three levels of script frequency, with only two correlations reaching significance. In contrast, a strong positive relationship was found between centrality and distinctiveness. The correlations ranged between .34 and .82 across the three levels of script frequency, with 12 of the 15 correlations reaching significance.

\section{DISCUSSION}

We conducted the present set of studies as a first step toward exploring a frequency-based theory of script representation-by collecting frequency-based data on daily activities and their scripts. We found that, overall, the number of events generated in a script increased with increasing script frequency, suggesting that some aspect of script representations may be subject to frequency effects, like other domains of knowledge (Grafman, 1995). However, an age group $\times$ script frequency interaction suggested that this may have been more the case for the young and middle-aged individuals than for the older individuals. Although older individuals may show greater 
Table 6

Intraclass Correlations Conducted on the Mean Centrality and Distinctiveness Rankings and the Mean Frequency of Reporting the 18 Events for Each of the 15 Scripts

\begin{tabular}{|c|c|c|c|}
\hline Scripts & Centrality & Distinctiveness & Frequency \\
\hline \multicolumn{4}{|l|}{ Low frequency } \\
\hline Going to a funeral & $.74 * * *$ & $.56^{*}$ & $.79 * * *$ \\
\hline Going scuba diving & .41 & $.58 *$ & $.66^{* *}$ \\
\hline Going to a theater audition & $.76^{* * * *}$ & $.70 * * *$ & $.72 * * *$ \\
\hline Being in a car accident & $.74 * * *$ & $.53 *$ & $.41 *$ \\
\hline Having your picture taken & $.54^{*}$ & $.73 * *$ & $.70 * * *$ \\
\hline \multicolumn{4}{|l|}{ Moderate frequency } \\
\hline Going bowling & $.77 * * *$ & $.77 * * *$ & $.67 * * *$ \\
\hline Going to the dentist & $.71 * *$ & $.76 * * *$ & $.65^{* *}$ \\
\hline Shopping for clothes & .41 & $.69 * *$ & $.74 * * *$ \\
\hline Giving a party & $.73 * * *$ & $.66 * *$ & $.57 *$ \\
\hline Painting a house & $.57 *$ & $.63 * *$ & $.65^{* *}$ \\
\hline \multicolumn{4}{|l|}{ High frequency } \\
\hline Getting ready for work & $.61 * *$ & $.46^{*}$ & $.72 * * *$ \\
\hline Doing the laundry & $.70 * *$ & $.54 *$ & $.81 * * *$ \\
\hline Shopping for groceries & $.69 * *$ & $.72 * * *$ & $.66^{* * *}$ \\
\hline Going out to dinner & $.52 *$ & $.78 * * *$ & $.71 * * *$ \\
\hline Putting a child to bed & $.71 * *$ & $.55^{*}$ & $.60 * *$ \\
\hline
\end{tabular}

frequency effects when naming words (Spieler \& Balota, 2000) or completing word stems (Ryan, Ostergaard, Norton, \& Johnson, 2001), our script generation task differs in that it does not rely on external cuing for each event generated. Also, individuals may rely on personal experience when generating scripts. It may be the case that the older individuals showed little effect of script frequency on script generation because they had lived longer and had greater experience with each of our script activities. Consequently, the older individualsmay have had a larger "database" of events available to draw from during script generation. Therefore, the 3-min time limit that we imposed on script generation may have actually attenuated the script frequency effect for the older individuals because it constrained the number of events that could be generated for the high-frequency scripts. Of course, this explanation is speculative.

With respect to the correlational data, we found a high degree of consistency among the three age groups as to which events were most likely to be generated in each script. Also, we found no age differences in the proportion of idiosyncratic events generated, at any of the three levels of script frequency, again suggesting a certain amount of

Table 7

Rank Order Correlations Among the Proportional Rankings for Centrality and Distinctiveness and the Frequency of Reporting an Event for the 18 Most Frequently Generated Events in Each Script in Study 2, Collapsed Across the Three Age Groups

\begin{tabular}{|c|c|c|c|}
\hline Scripts & $\begin{array}{c}\text { Centrality } \\
\text { and Frequency }\end{array}$ & $\begin{array}{l}\text { Distinctiveness } \\
\text { and Frequency }\end{array}$ & $\begin{array}{c}\text { Centrality } \\
\text { and Distinctiveness }\end{array}$ \\
\hline \multicolumn{4}{|l|}{ Low frequency } \\
\hline Going to a funeral & .00 & -.09 & $.59 * *$ \\
\hline Going scuba diving & -.30 & -.19 & $.66^{* *} *$ \\
\hline Going to a theater audition & -.05 & -.03 & $.79 * * * *$ \\
\hline Being in a car accident & -.41 & -.45 & $.60 * *$ \\
\hline Having your picture taken & -.24 & .10 & $.70 * * *$ \\
\hline \multicolumn{4}{|l|}{ Moderate frequency } \\
\hline Going bowling & -.25 & -.19 & $.69 * * *$ \\
\hline Going to the dentist & -.36 & $-.48 *$ & $.73 * * *$ \\
\hline Shopping for clothes & .12 & .05 & .45 \\
\hline Giving a party & $-.56 * *$ & -.44 & $.71 * * *$ \\
\hline Painting a house & -.45 & -.43 & $.78 * * * *$ \\
\hline \multicolumn{4}{|l|}{ High frequency } \\
\hline Getting ready for work & -.42 & -.21 & .40 \\
\hline Doing the laundry & $-.66 * *$ & $-.67 * *$ & $.82 * * * *$ \\
\hline Shopping for groceries & -.42 & .08 & .34 \\
\hline Going out to dinner & $-.53 *$ & -.30 & $.63 * *$ \\
\hline Putting a child to bed & -.22 & -.26 & $.82 * * * *$ \\
\hline
\end{tabular}

Note- $N=18$. Proportional rank values increased with decreasing levels of centrality/distinctiveness. $* p<.05 . \quad * * p<.01 . \quad * * * p<.001 . \quad * * * * p<.0001$. 
overlap in script representation among the three age groups. Finally, we found that self-reports of recency of engaging in an activity from Study 2 mapped onto frequency of reporting an activity in Study 1. Furthermore, we found no evidence of age or gender bias in the frequency or recency of engaging in the 15 activities reported here.

With respect to our rankings of centrality and distinctiveness, we found a strong relationship between the two. Although Galambos (1983) did not find a similar relationship between centrality and distinctiveness, there are a number of possible explanations for the differences between his findings and our own. The most obvious difference is that we had individuals rank their own events immediately after they had generated their scripts, whereas Galambos had different groups of individuals rank events in scripts that were preselected for them. Also, our correlations were based on 18 events in each script, whereas his were based on 12 events in each script, so we may have had greater power to detect a relationship between centrality and distinctiveness. It may also be the case that the magnitude of the relationship between centrality and distinctiveness was exaggerated by the restricted range of frequency that we chose (i.e., the 18 most frequently generated events). An examination of Table 7 suggests that any demand characteristics that may have been produced by our having individuals rank their own events cannot completely explain the magnitude of the relationship that we found between centrality and distinctiveness. The relationship was not perfect, for any of the scripts. Furthermore, the correlations between centrality and frequency increased across script frequency (means of .20, .30, and .45 for low-, moderate-, and high-frequency scripts, respectively). In contrast, the correlations between distinctiveness and frequency did not show the same pattern (means of .13, .30, and .27 for low-, moderate- and highfrequency scripts, respectively), suggesting that the participants did not just assign the same centrality and distinctiveness rank value to each event.

In general, our results were similar across the three age groups. It might be argued that some of the results reported here could be a function of the methodology used-for example, the time limits imposed or the scoring procedure. The 3-min time limit that we imposed on generation may have discouraged individuals from recording idiosyncratic events, because those events would have required greater recording time than that needed for the more frequently experienced events. However, Bower et al. (1979) found a comparable proportion of idiosyncratic events in their study - with no time limits imposed. A closer inspection of their scoring procedure revealed that we similarly combined analogous events into single events. Finally, some researchers have found that script generation and judgments about underlying knowledge structures vary as a function of instructions or task constraints (Hess, 1992; Rips, 1989; Ross \& Berg, 1992).

The present set of studies may not be able to answer questions about the nature of script representation (e.g., whether scripts are stored in a sequential or a categorical manner). However, these studies did provide us with evidence that script representations may be subject to frequency effects, like other domains of knowledge (Grafman, 1995). More important, the present set of studies has provided us with a set of age and gender neutral materials that may help researchers study the nature of script representations in a more systematic fashion.

\section{REFERENCES}

Аввотt, V., Black, J. B., \& Smith, E. E. (1985). The representation of scripts in memory. Journal of Memory \& Language, 24, 179-199.

Barsalou, L. W., \& Sewell, D. R. (1985). Contrasting the representation of scripts and categories. Journal of Memory \& Language, 24, 646-665.

Bower, G. H., Black, J. B., \& Turner, T. J. (1979). Scripts in memory for text. Cognitive Psychology, 11, 177-220.

Galambos, J. A. (1983). Normative studies of six characteristics of our knowledge of common activities. Behavior Research Methods \& Instrumentation, 15, 327-340.

Galambos, J. A., \& RIPs, L. J. (1982). Memory for routines. Journal of Verbal Learning \& Verbal Behavior, 21, 260-281.

Grafman, J. (1995). Similarities and distinctions among current models of prefrontal functions. In J. Grafman \& K. J. Holyoak (Eds.), Structure and functions of the human prefrontal cortex (Annals of the New York Academy of Sciences, Vol. 769, pp. 337-368). New York: New York Academy of Sciences.

Grafman, J., Thompson, K., Weingartner, H., Martinez, R., Lawlor, B. A., \& Sunderland, T. (1991). Script generation as an indicator of knowledge representation in patients with Alzheimer's disease. Brain \& Language, 40, 344-358.

Haberlandt, K., \& Bingham, G. (1984). The effect of input direction on the processing of script statements. Journal of Verbal Learning \& Verbal Behavior, 23, 162-177.

Hess, T. M. (1992). Adult age differences in script content and structure. In R. L. West \& J. D. Sinnot (Eds.), Everyday memory and aging (pp. 87-100). New York: Springer-Verlag.

Hue, C., \& ERICKSON, J. R. (1991). Normative studies of sequence strength and scene structure of 30 scripts. American Journal of Psychology, 104, 229-240.

Light, L. L. \& Anderson, P. A. (1983). Memory for scripts in young and older adults. Memory \& Cognition, 11, 435-444.

Miller, G. A., Galanter, E., \& Pribram, K. H. (1960). Plans and the structure of behavior. New York: Holt, Rinehart \& Winston.

Nottenburg, G., \& Shoben, E. J. (1980). Scripts as linear orders. Journal of Experimental Social Psychology,16, 329-347.

RIPS, L. J. (1989). Similarity, typicality, and categorization. In S. Vosniadou \& A. Ortony (Eds.), Similarity and analogical reasoning (pp. 21-59). New York: Cambridge University Press.

Ross, B. L., \& Berg, C. A. (1992). Examining idiosyncracies in script reports across the life span: Distortions or derivations of experience. In R. L. West \& J. D. Sinnot (Eds.), Everyday memory and aging (pp. 38-53). New York: Springer-Verlag.

Ryan, L., OSTERgaARD, A., Norton, L., \& Johnson, J. (2001). Search and selection processes in implicit and explicit word-stem completion performance in young, middle-aged, and older adults. Memory \& Cognition, 29, 678-690.

SchANK, R., \& ABELSON, R. (1977). Scripts, plans, goals and understanding. Hillsdale, NJ: Erlbaum.

Shrout, P. E., \& Fleiss, J. L. (1979). Intraclass correlations: Uses in assessing rater reliability. Psychological Bulletin, 86, 420-428.

Sirigu, A., Zalla, T., Pillon, B., Grafman, J., Agid, Y., \& Dubois, B. (1995). Selective impairments in managerial knowledge following pre-frontal cortex damage. Cortex, 31, 301-316.

Sirigu, A., Zalla, T., Pillon, B., Grafman, J., Agid, Y., \& Dubois, B. (1996). Encoding of sequence and boundaries of scripts following prefrontal lesions. Cortex, 32, 297-310.

SPIELER, D. H., \& BALOTA, D. A. (2000). Factors influencing word naming in younger and older adults. Psychology \& Aging, 15, 225-231. 


\section{NOTE}

1. The following random-effects intraclass correlation formula from Shrout and Fleiss (1979) was used to calculate the correlations in Table 6:

$$
\mathrm{ICC}=\frac{\mathrm{BMS}-\mathrm{EMS}}{\mathrm{BMS}+(k-1) \mathrm{EMS}+\frac{k(\mathrm{JMS}-\mathrm{EMS})}{n},}
$$

where BMS is the between-item error; EMS is the residual error; JMS is the between-group error; $k=$ number of age groups (3) and $n=$ number of items (18).

The following $F$ test from Shrout and Fleiss (1979) was used to test the significance of the correlations in Table 6:

APPENDIX A

Study 1 Sample Journal Sheet as it Appeared in the Take-Home Booklet

Examples:
Monday: 6/15/98
1AM: sleep
2AM: $\quad$ same as above
3AM: $\quad$ same as above
4AM: $\quad$ same as above
5AM: $\quad$ same as above
6AM: woke up, had a cup of tea, did exercises
7AM: $\quad$ showered, dressed for work
8AM: made and ate breakfast, made lunch, drove to work
9AM: $\quad$ arrived at work, made coffee, opened mail
10AM: answered correspondence and phone messages
11AM: worked on profit and loss spreadsheets
Noon: ate lunch
1PM: met with boss about new employee
2PM: trained new employee
3PM: same as above
4PM: scheduled several business meetings for the week
5PM: left work, stopped by the market on the way home
6PM: $\quad$ unpacked groceries, cooked dinner
7PM: ate dinner, washed the dishes
8PM: listened to music and read
9PM: got clothes ready for the next day, called a friend
10PM: did yoga, got ready for bed
11PM: went to bed
Midnight:sleep

APPENDIX B

Study 2 Sample Script as It Appeared in the Booklet

This booklet contains 15 pages that have the name of an activity printed at the top of each page. We want you to write down the sequence of events associated with each activity to the best of your knowledge, from the very beginning of it until its completion. You will have 3 minutes to write down the events for each activity. Please use only the wide lines on the left side of each page.

Do not turn any pages until the experimenter tells you to do so.

For example, if we asked you to write down the sequence of events involved in touring a farm, it might look like this:

1. Call farm and schedule an appointment.

2. Send in check.

3. Put kids in the car.

4. Drive to the farm.

5. Arrive at farm and check-in at farmhouse.

6 . Listen to safety instructions.

7. Walk to barn.

8. Watch workers milk and feed the cows.

9. Walk to chicken coop.

10. Feed chickens and play with chicks. 


\section{APPENDIX B (Continued)}

11. Walk to the pig pen.

12. Feed the pigs.

13. Walk over to the sheep barn.

14. Help with shearing the sheep.

15 . Go on a hay ride around the fields.

16. Stop in corn field and pick ears of corn.

17. Bring corn back to the farmhouse.

18. Have a cookout.

19. Stop at the souvenir shop.

20. Get back in car and drive home.

\section{APPENDIX C \\ Centrality and Distinctiveness Ranking Instructions Read by the Experimenter in Study 2}

\section{Centrality}

Now we want you to go back to each activity starting on page 1 and rate the centrality, or relative importance, of each of the events that you generated. For example, buying a ticket is central to traveling on a plane because you cannot board a plane without a ticket. However, checking your luggage is not so central, because many people take carry-on luggage. Please place a " 1 " next to the event that is most central to the activity, " 2 " next to the event that is the next most central, and so on until all of the events have been given a number that represents their centrality in the activity. Place this number on the line in the first column to the right of each event (demonstrated in a blank booklet). Please do this for each activity.

\section{Distinctiveness}

Now please go back to each activity starting on page 1 and rate the distinctiveness of each of the events that you generated. An event is distinctive to an activity if you have difficulty thinking about it as part of another activity. For example, buying a ticket is not distinctive to traveling on a plane because it could be part of other activities as well - such as going to the theater to see a play. In contrast, putting your tray in an upright position is distinctive to traveling on a plane, because it's difficult to think of another activity that would include that particular event. Please place a " 1 " next to the event that is most distinctive to the activity, " 2 " next to the event that is the next most distinctive, and so on until all of the events have been given a number that represents their distinctiveness. Place this number on the line in the second column to the right of each event (demonstrated in a blank booklet). Please do this for each activity.

\section{When They Last Did Activity}

The final thing that we want you to do is to tell us - in hours, days, weeks, months, or yearshow long it has been since you last engaged in each of the activities. Please place your answer on the single line at the top of each sheet (demonstrated in a blank booklet). For example, if you just engaged in one of the activities yesterday, you would write down " 1 day" on this line. If you are certain that you have never engaged in an activity then place a "Never" on the line. Please do this for each activity.

(Manuscript received November 8, 2001; 